\title{
INVESTIGATING THE APPLICABILITY OF UNMANNED AERIAL VEHICLES (UAV) PHOTOGRAMMETRY FOR THE ESTIMATION OF THE VOLUME OF STOCKPILES
}

\author{
Oluibukun Gbenga Ajayi (1) , John Ajulo \\ Department of Surveying and Geoinformatics, Federal University of Technology, Minna, Nigeria
}

Manuscript received: September 30, 2020

Revised version: January 10, 2021

\begin{abstract}
Ajayi O.G., Ajulo J., 2021. Investigating the applicability of unmanned aerial vehicles (UAV) photogrammetry for the estimation of the volume of stockpiles. Quaestiones Geographicae 40(1), Bogucki Wydawnictwo Naukowe, Poznań, pp. 25-38. 5 tables, 6 figs.

ABSTRACT: Accurately estimating the volume of earthworks is very important in mining engineering and construction. This estimation can be difficult because of the morphological condition of the stockpiles, hence, devising simpler, yet accurate methods of stockpile volume estimation is still a research problem in mining. Two non-invasive survey methods were compared in this research: the conventional ground-based and UAV-approach, for the survey of a twin-stockpile of gravel using Leica TS06 Total Station and DJI Mavic Air UAV, respectively. About 128 images of the area were acquired at $50 \mathrm{~m}$ flying height and $75 \%$ overlap during the flight mission. The images were processed using Agisoft Metashape Pro; a digital photogrammetric software, and the DEM obtained was used for the volume estimation. The total station data was also processed in ArcGIS to generate a TIN-model from which the volume was also estimated. The volume estimated from the TIN-model was compared with the volume estimated from the UAV-based DEM, using the volume obtained from the mill-machine as the standard. The obtained result shows that while $2750 \mathrm{~m}^{3}$ was obtained as the cumulative volume from the mill machine, the UAV approach yielded $2686.252 \mathrm{~m}^{3}$ and the ground survey approach gave $2830.713 \mathrm{~m}^{3}$. The percentage difference between the two methods compared to the actual volume is $2.94 \%$ and $-2.31 \%$, respectively. These results, and the result of the processing time analysis show that UAV approach is both accurate and time economical, which attests to the potentials of low-cost UAVs to provide robust alternative to the time-consuming and rigorous ground survey approach.
\end{abstract}

KEY WORDS: stockpiles, earthworks, volumetric computations, ground survey, UAV photogrammetry

Corresponding Author: Oluibukun Gbenga Ajayi, ogbajayi@gmail.com

\section{Introduction}

Stockpile is a term used for a large collection of mining and construction materials, such as sand, gravel, asphalt, large rocks, and so on, that are stored in reserve for future use or at time of shortage. Stockpiles and storage areas in most engineering earthwork projects are generally measured by manual techniques (David et al. 2015). Volumetric measurement is of utmost importance to Mine Engineers and it is primarily for the determination of the actual amount of materials required to fill up large scale dig outs such as quarries or borrow pits, and to determine the change in the volume of the quantity over time.

Generally, the predominant method of acquiring necessary data needed for the estimation of volumetric information is the conventional terrestrial or ground based survey method where

\section{sciendo}


Theodolites and Level instruments, Total Station, Global Navigation Satellite Systems, and so on, are used. The practical field procedure of the conventional method requires that the location and level of the top and foot (base) of the stockpiles, and any other change in grade or topography is obtained by the Surveyor with the aid of any of the aforementioned survey instruments. The acquired $X, Y$, and $Z$ data are processed into 3D Models from where the volume of the stockpiles can be estimated. For example, the total station is an electronic transit theodolite integrated with an Electronic Distance Meter (EDM) to read slope distances from the instrument to a particular point (Kavanagh and Glenn 1996). These data are recorded electronically to an accuracy of \pm 20 $\mathrm{mm}$ and then processed in order to generate 3D model of the stockpile from which the volume of the earthworks will be determined. Apart from the dangers posed by the risky terrain of mining sites, this method has proved to be expensive and time consuming, hence the need for alternative approaches.

Aerial photogrammetry includes the use of manned aerial vehicle or a remotely controlled or an autonomous vehicle designed to acquire specific image data about a particular area or site. It offers geomatics a real time application and a less costly approach to the classical method of aerial photogrammetry (Eisenbeiß 2009). More recently, attention has shifted to the applications of Unmanned Aerial System (UAS) - photogrammetry due to its many advantages, some of which include its miniaturised size, which makes it portable and easy to manoeuvre, cost effectiveness, time efficiency, ability to acquire images of high spatial resolution, and so on. The component of an Unmanned Aerial Vehicle includes a ground-based control station, a digital camera, lithium-polymer batteries, an autonomous control and an onboard communication system between the ground station and the drone. UAVs are recommended for minor terrain mapping in order to give quick update for mapping purposes, for military, exploration (Ding et al. 2015), 3D mapping (Ajayi et al. 2017), precision agriculture (Ioanna and Apostolos 2015, Ajayi et al. 2018), post-earthquake quick damage assessment (Baiocchi et al. 2013), and in many other applications. More specifically, UAVs are fast gaining wide acceptance in engineering applications and estimation of the volume of earthworks (Raeva et al. 2016, Propeller 2018). Ab Rahman et al. (2017) emphasised that in recent times, the potential of UAV in surveying and engineering applications has increased due to technological advancement, as it is capable of executing complex tasks within a short time and in dangerous and inaccessible terrains or environment.

Choosing the most appropriate technique and instrumentation for the field operation requisite for volume estimation is dependent on some factors such as, the purpose of the survey, accessibility, visibility, the topographical and morphological condition of the site, weather condition, safety, the level of accuracy, and the cost of the survey project.

Raeva et al. (2016), Ab-Rahman et al. (2017), and Stalin and Gnanaprakasam (2017) affirmed that the conventional methods of earthwork volume estimation are time consuming while also identifying difficulties in making geodetic measurements in remote area, and inability to obtain sufficient number of points for accurate surface modelling as the major problems associated with conventional methods. In surface mining industry, the use of terrestrial surveying equipment to obtain the spatial data required to compute the volume of earthworks is very difficult, error prone, and poses a great risk to safety in areas with unstable landforms. This makes it difficult for the Surveyor to acquire the needed data for mining documentation and volume estimation. Furthermore, the conventional surveying method of data capturing for volume estimation provide limited number of points, which affects the obtainable accuracy of surface modelling of the earthworks. Therefore, there is need for adoption of alternative methods that affords high density of points in 3D coordinates in order to improve the accuracy of the estimated volumes. Akwaowo et al. (2019) compared the stockpile volumes estimated from UAV Photogrammetry and Total Station data, and discovered that the accuracy obtainable from instruments or data sources that provide very dense points cloud is higher than the accuracy obtainable from instruments that provide less dense points cloud. With UAV approach of earthwork volume estimation, a sufficient number of points cloud can be obtained, which increases the accuracy of the surface models required for volume estimation. 
The aim of this paper is to investigate the applicability and suitability of UAS for the accurate estimation of the volume of stockpiles. The specific objectives are to:

1. survey the study site using a Total Station instrument and a UAV (drone) in order to acquire the spatial data necessary for 3D model generation,

2. estimate the volume of stockpiles from the 3D models generated from both approaches, and

3. compare the robustness of the two methods with respect to accuracy and time, using the actual volume obtained from the mill machine as the standard for the accuracy evaluation.

\section{Literature review}

With recent development in technology using aerial and terrestrial laser scanning systems, which has significantly improved measurement accuracy, and with more accurate surface modelling techniques, volume determination is becoming more robust and reliable. This development has made it indispensable for virtually all Geographic Information System (GIS) and Computer Aided Drawing and Design (CAD) to integrate techniques for volume computation using Delaunay triangulation, which produces unique results (Siriba et al. 2015). This method aids the generation of three-dimensional surface models like the Triangular Irregular Network (TIN), Digital Terrain Models (DTM), Digital Elevation Models (DEM) and Digital Surface Models (DSMs), which are important for volume estimation.

Different research efforts have been invested in the determination of suitable surveying instrument and method that will provide optimal results in volume estimation. Some of the explored methodologies include conventional ground based survey methods using Total Station, Global Navigational Satellite System (GNSS), Manned and Unmanned Aerial Systems (UAS), Light Detection and Ranging (LiDAR), which includes both airborne laser scanning (ALS) and terrestrial laser scanning (TLS), and so on. These methods broadly fall into the categories of invasive and non-invasive methods, or contact and non-contact methods.

Non-contact methods of mass data collection using laser scanning with Leica P40 and aerial photogrammetry using DJI Phantom 4 Pro UAV to monitor mass movement caused by torrential rainfall on the Talus Cones in the Alpine Terrain in High Tatras of Slovakia was deployed by Urban et al. (2019). The results of these measurements were compared using direct comparison of point cloud, and the overall suitability of both methods for measurement in such terrain was evaluated. The standard deviation of the difference of surface determination, which was represented by the point cloud is about $0.03 \mathrm{~m}$, proved that the accuracy is sufficient for the purpose of monitoring Talus Cones and the use of lowcost UAS photogrammetry is less difficult and associated with lower risk of damage, since the equipment is not very expensive. The research concluded that UAS is more suitable for mapping and terrain monitoring when compared to terrestrial laser scanning.

Similarly, the sediment volume transported by a major debris flow event in the Halltal, Austrian Alps, using a combination of terrestrial and airborne laser scanning was estimated by Bremer and Sass (2012), which proved to be suitable for accurate extreme event quantification. Kociuba (2017) also applied high-resolution repeat Terrestrial Laser Scanning (TLS) surveys in the assessment of erosion and deposition volumes in the valley of the Tyvjobekken Creek. Leica Scan Station C10 and Real Time Kinematic Global Positioning System (GPS RTK) was used to acquire the used data across the estuarial part of the valley with an area of $92,631 \mathrm{~m}^{2}$ during the culmination of melt-water seasons in 2010 and 2013. The result of the high definition TLS surveys showed great registration accuracy of 0.009 $\mathrm{m}$ during field campaign conducted in the year 2010, which was better than the registration accuracy obtained in the year $2013(0.02 \mathrm{~m})$.

In addition, Nourbakhshbeidokhti et al. (2019) reviewed and compared four methods of TLS analysis by quantifying the uncertainty in TLS-derived products such as DEM of difference (DOD), Cloud to Cloud (C2C), Cloud to Mesh (C2M), and Multiple Model to Model Cloud Comparison (M3C2). They also developed a workflow for the estimation of topographic and volumetric changes in channel sedimentation after disturbance. While the developed workflow aids the estimation of uncertainties in the methods of data collection and analysis for 
topographic and volumetric change analysis, the errors estimated from the total volumetric change implied increased errors in the conversion of point clouds into a surface by $\mathrm{C} 2 \mathrm{M}$ and $\mathrm{DOD}$, whereas $\mathrm{C} 2 \mathrm{C}$ and $\mathrm{M} 3 \mathrm{C} 2$ proved to be generally simpler, efficient, and accurate techniques for evaluating topographic changes.

Furthermore, Blistan et al. (2020) tested the possibility of deploying unconventional methods such as digital close-range photogrammetry and TLS for the determination of bulk density of raw materials under in situ conditions using the perlite deposit Lehôtka pod Brehmi in Slovakia as a case study. Comparing the results obtained from the field in situ measurements and laboratory measurements showed only a $4.5 \%$ difference in results between the two methods for determining the density of heterogeneous raw materials, confirming the accuracy of the used in situ methods.

Also, both Borgelt et al. (1996) and Lin (2004) compared the accuracy obtainable from Total Stations and Global Positioning System (GPS) receivers deployed in Real Time Kinematic (RTK) mode. The result shows that both methods are comparable in terms of accuracy while each of the two methods has its own peculiar disadvantages.

Further, Marco et al. (2012) proposed the use of high resolution DEM for the improvement of the accuracy of the earthwork volume estimation, using the proposed forest roads as a case study. A computerized model was developed and applied to three hypothetical forest road layouts with different terrain configuration and ground slopes. The effect of various cross-section spacings on the accuracy of the earthwork volumes was also examined with an assumption that 1-meter spacing provides the most probable value of the volume of the earth work. The results, which was also compared with the results obtained from the traditional end-area method, indicated that increase in cross-section spacing leads to a decrease in the accuracy of earthwork volume due to lack of ability to effectively capture terrain variation with increased cross-section spacing. Hence, short cross-section spacing is recommended for the earthwork volume estimation for the planning of roads, especially roads that are located on a hilly and rugged terrain.

In addition, Pflipsen (2006) tested the accuracy and time expended for the survey of a pile of sand using the Total Station equipment (Leica TS1200) and laser scanner (Leica HDS 2500). The obtained result showed that almost similar horizontal and vertical coordinate accuracy was achieved (below $9 \mathrm{~mm}$ ) in both methods. The time consumed for the laser measurements was 7 minutes short of the time expended using Leica TS1200 Total Station, which shows that using a laser scanner provides result faster than when a Total Station is used. Furthermore, Arango and Morales (2015) presented the result of the survey of a quarry where a DJI Phantom 2 vision plus UAV was used together with Leica TS-02 Total Station. The result of survey indicated that the volume of the stockpile was estimated as $11831.20 \mathrm{~m}^{3}$ when the Total Station equipment was used while the UAV approach produced $11423.58 \mathrm{~m}^{3}$ as the volume of the stockpile. The actual volume was $11500.00 \mathrm{~m}^{3}$. From the comparison, it was deduced that the difference between the Total Station-based volume and the actual volume was $2.88 \%$, while the difference between the UAV-based volume and the actual volume was $-0.67 \%$, which implies that the UAV approach gave a more accurate result.

Similarly, Fitzpatrick (2016) also compared the cost of mapping using UAS with traditional methods of data acquisition. The findings of the comparative analysis proved that UAS provides a more accurate result when compared to the use of cross-sectional method of volume estimation and topographic mapping. The cost of survey and the total execution time using the UAS was also found to be less when compared to the cross-sectional method. Again, Fitzpatrick (2016) compared the UAS and a manned aircraft equipped with LiDAR for photogrammetry, but could not affirm that any of the methods is more accurate because the time and flight data of the manned aircraft were not available; thus, assumptions were only made that UAS took less time with lower cost of operation, but its accuracy is poorer than the LiDAR equipped manned aircraft for topographic mapping.

Furthermore, Kovanič et al. (2020) investigated the applicability and suitability of high-resolution DEM obtained using ALS and UAS (SfM), for the identification of changes and monitoring the development of selected geohazards in the alpine environment using TLS as the reference method. The findings of the research shows and concluded that UAS presents the most suitable 
technology in terms of flexibility, speed, inexpensiveness, and provision of high point cloud density. On the other hand, while the TLS is application problematic, with high purchase cost of instrument, and its need for measurements to be performed from higher number of scanning stations which extends the time required for measurements in the field, the publicly available (open source) ALS data showed comparable accuracy (higher than stated by the provider), limited only by the lower density and update interval of the data.

Similarly, a novel methodological approach based on a the combined use of TLS and closerange photogrammetry from a UAV for generating a high-resolution point cloud and digital elevation model (DEM) of a complex alpine terrain was developed by Šašak et al. (2019). The approach was demonstrated using a small study area in the upper part of a deglaciated valley in the Tatry Mountains of Slovakia, by using UAV point cloud to supplement the TLS data in areas of insufficient TLS data coverage. The generated high-resolution DEM was compared to open source DEMs such as the SRTM DEM, TanDEM-X and national DMR3 DEM products, with the findings confirming an excellent applicability in a wide range of geomorphologic applications.

Finally, Raeva et al. (2016) also compared the result obtained when a Leica viva G08 (dual-frequency GPS with accuracy of $-5 \mathrm{~mm}+0.5$ ppm RMS horizontal and $10 \mathrm{~mm}+0.5$ ppm vertical) and eBee fixed wing UAV was used for the survey of a quarry situated in Lovech region of Bulgaria. While an estimated volume of 12,606 $\mathrm{m}^{3}$ was obtained from the DGPS approach, an estimated volume of $12,749 \mathrm{~m}^{3}$ was obtained from the UAV approach, which shows a variation of $1.1 \%$, and attests to the robustness of UAVs in volume estimation.

From the reviewed literature, it can be deduced that while a comparative analysis of the estimation of the volume of earthworks using UAV approach and other conventional approaches have been conducted by different researchers; most of such investigations are only with respect to the accuracy of the methods. There is relatively sparse evidence of past documented efforts to conduct such comparative analysis with respect to both accuracy and time in the reviewed literature, hence, a gap this research seeks to fill.

\section{Materials and methods}

\section{Study Area}

The study site for this research is a quarry site located in Mpape district of Bwari Local Government Area, Abuja, the Federal Capital Territory of Nigeria. It is situated geographically on Latitude $9^{\circ} 8^{\prime} 27^{\prime \prime} \mathrm{N}$ of the equator and

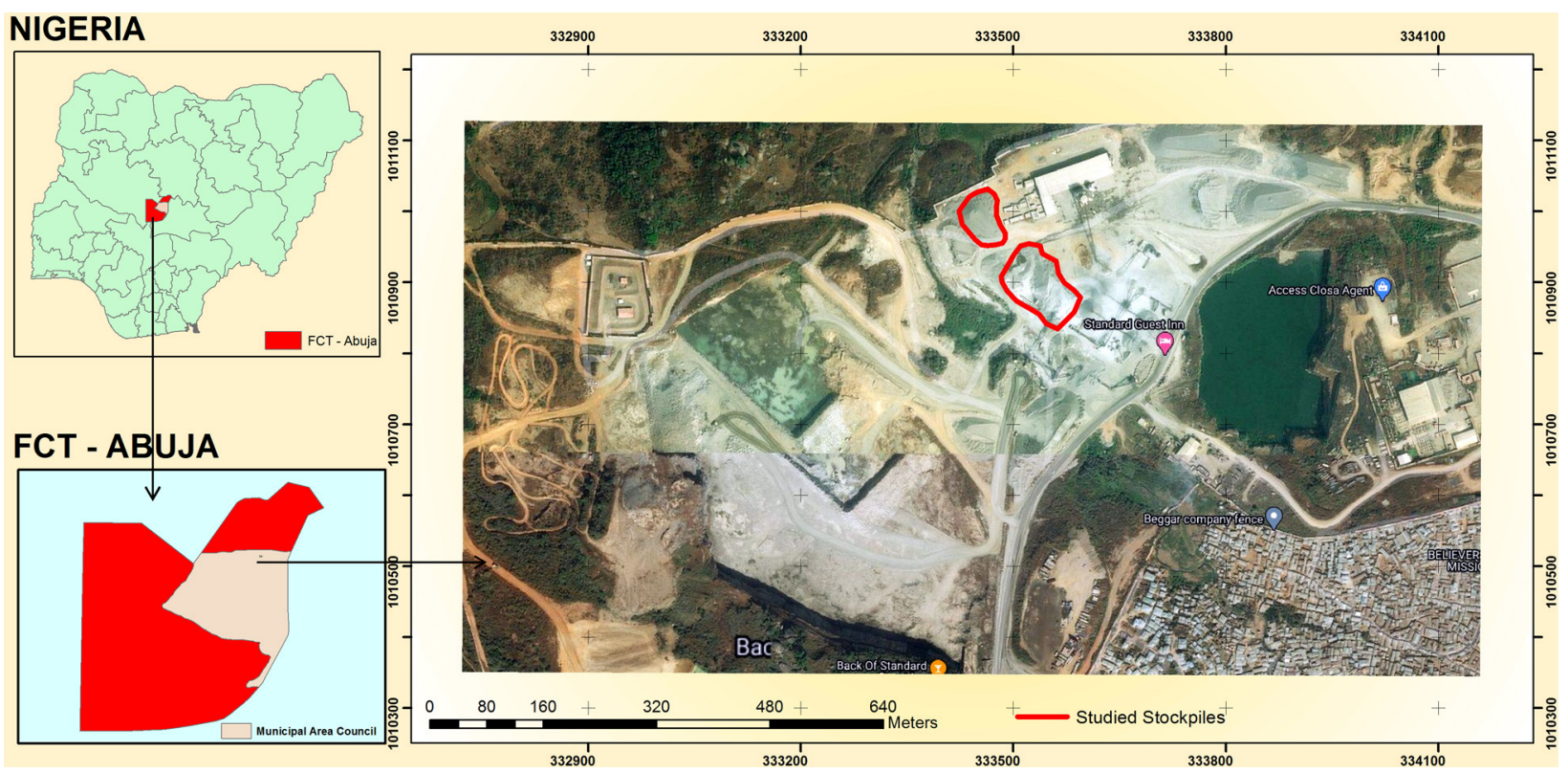

Fig. 1. Diagrammatic representation of the study area. 
Longitude $7^{\circ} 29^{\prime} 03^{\prime \prime}$ E of the Greenwich Meridian. The diagrammatic description of the study area is presented as Figure 1.

\section{Instrumentation and software}

A Leica FlexLine TS06 Total Station (TST) and a DJI Mavic Air UAV (a quadcopter) were used to survey the twin stockpiles in order to acquire the spatial data required for the estimation of the volume of the stockpiles. The Total Station is inbuilt with an EDM option, with a weight of $5.1 \mathrm{~kg}$, including the tribrach and a battery, which can last for about $30 \mathrm{hrs}$ when fully charged. The UAV on the other hand is a light weight instrument and it weighs only about $430 \mathrm{~g}$. It is equipped with an onboard GNSS sensor, which it uses for real time positioning and to capture geo-tagged images. The UAV moves at a speed of $4 \mathrm{~m} / \mathrm{s}$ and was flown at a flight height of $50 \mathrm{~m}$ above the object of capture during the image data acquisition. The technical parameters of the deployed UAV are presented in Table 1.

For the software used, while the spatial data acquired with the aid of the TST was processed in ArcGIS software environment, the geotagged images acquired by the drone were processed using Agisoft Metashape Pro 1.5.3; a digital photogrammetric software.

\section{Data Acquisition and Processing}

Figure 2 presents the descriptive chart of the adopted methodology from data acquisition to analysis. Using pre-marking approach, ground control points were fixed at strategic positions from the foot of the stockpiles using white marked plates as shown in Figure 3, and their coordinates

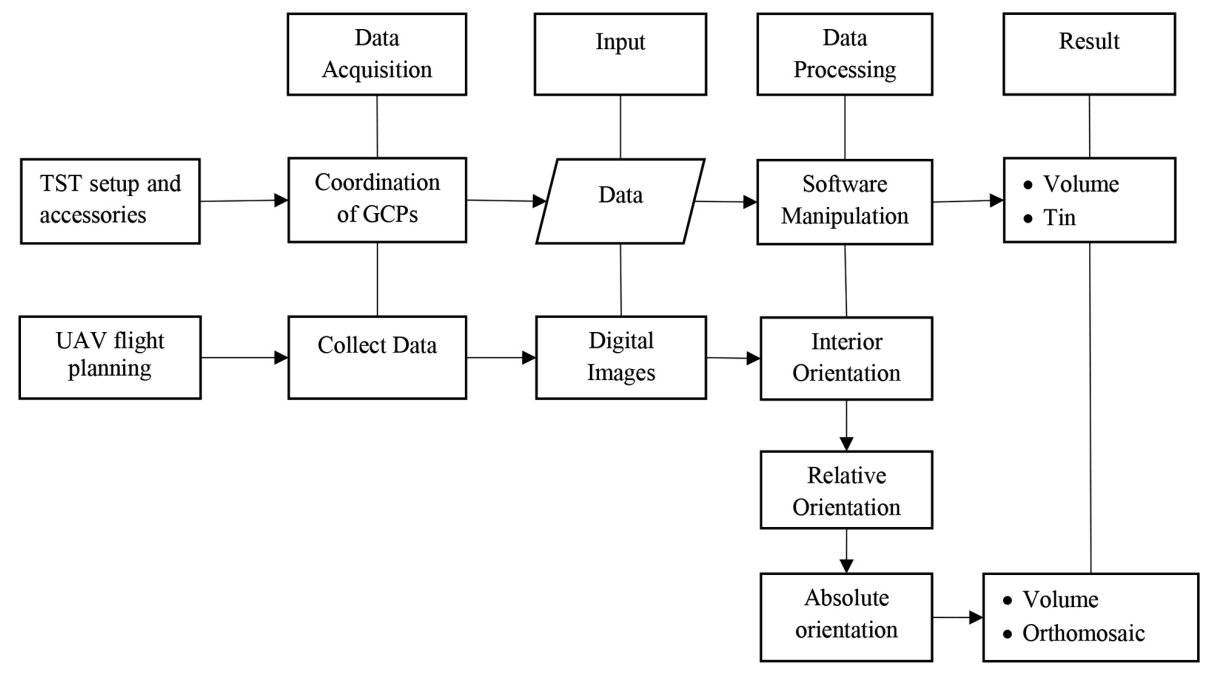

Fig. 2. A chart of the methodology.

Table 1. Technical Parameters of DJI Mavic Air UAV.

\begin{tabular}{|c|c|}
\hline Components & Parameter \\
\hline Aircraft & $\begin{array}{l}\text { Take-off Weight: } 430 \mathrm{~g} \text {, GNSS (GPS + GLONASS), internal storage (8 GB), operating tem- } \\
\text { perature range }\left(0-40^{\circ}\right) \text {, maximum flight distance }(10 \mathrm{~km}) \text {, maximum wind speed resistance } \\
(29-38 \mathrm{kph}) .\end{array}$ \\
\hline Remote Controller & $\begin{array}{l}\text { Operating frequency }(2.400-2.4835 \mathrm{GHz}, 5.725-5.850 \mathrm{GHz}) \text {, operating temperature }\left(0-40^{\circ}\right) \text {, } \\
\text { battery }(2970 \mathrm{mAh}) \text {. }\end{array}$ \\
\hline Gimbal & $\begin{array}{l}\left.\text { Mechanical range (Tilt: }-100^{\circ} \text { to } 22^{\circ} \text {, Roll: }-30^{\circ} \text { to } 30^{\circ} \text {, Pan: }-12^{\circ} \text { to } 12^{\circ}\right) \text {, stabilization ( } 3 \text {-axis, } \\
\text { that is, tilt, roll and pan), controllable range }\left(-90^{\circ} \text { to } 0^{\circ} \text { as default setting, }-90^{\circ} \text { to }+17^{\circ} \text { as ex- }\right. \\
\text { tended setting). }\end{array}$ \\
\hline Camera & $\begin{array}{l}\text { Sensor (1/2.3" CMOS), Lens (FOV: } 85^{\circ}, 35 \mathrm{~mm} \text { format equivalent to } 24 \mathrm{~mm} \text {, aperture: } \mathrm{f} / 2.8 \text {, } \\
\text { shooting range: } 0.5 \mathrm{~m} \text { to } \infty \text { ), photo format (JPEG/DNG (RAW)), supported file format (FAT32). }\end{array}$ \\
\hline $\begin{array}{l}\text { Intelligent flight } \\
\text { battery }\end{array}$ & Capacity (2375 mAh), voltage (11.55 v), Battery type (LiPo 3S), net weight (140 g) \\
\hline $\begin{array}{l}\text { Mobile device } \\
\text { control }\end{array}$ & $\begin{array}{l}\text { Operating frequency }(2.400-2.4835 \mathrm{GHz}, 5.725-5.850 \mathrm{GHz}) \text {, maximum transmission distance } \\
(80 \mathrm{~m}) \text { with height of } 50 \mathrm{~m} \text {. }\end{array}$ \\
\hline
\end{tabular}




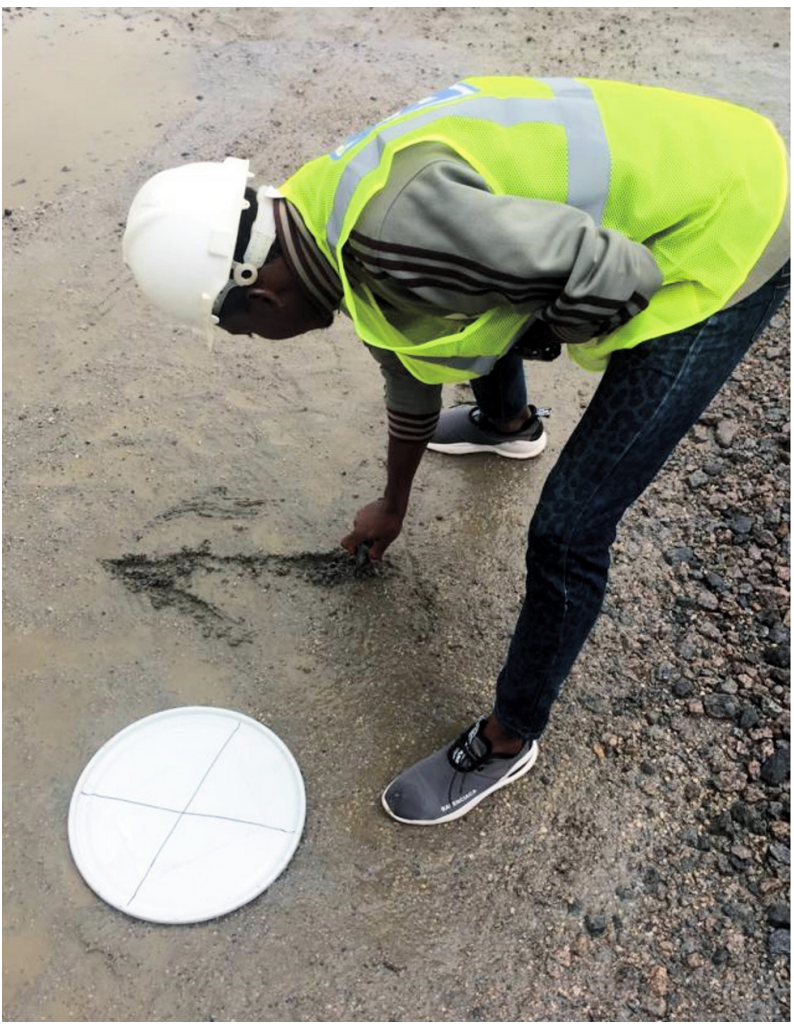

Fig. 3. Ground Control Point (GCP) station selection and marking.

were obtained using the TST instrument to an accuracy of $5 \mathrm{~mm}$ height. The total area on which the stockpile lies is about $1530.00 \mathrm{~m}^{2}$.

Attempt was made to ensure that the two methods of survey were executed the same day so as to be sure that the stockpiles captured using the two methods are the same and that the stockpiles were not significantly altered either by natural or anthropogenic forces.

For the deployment of the UAV for image data capture, the flight plan was first designed where all necessary parameters were set and specified. The camera angle was set at $45^{\circ}$ to ensure that all the details of the stockpiles were captured. The flight height of $50 \mathrm{~m}$, side overlap of $70 \%$ and front overlap of $80 \%$ were specified for the automatic data capture. Electronic speed control test was conducted, and all the UAV accessories such as its rotor blades, camera holder and camera, and other non-imaging sensors of the drone were tested for optimal functionality. A suitable UAV base station was then identified for the take-off and landing of the drone. The UAV data was acquired in the early hours of the day when the weather was fair, with light breeze and low precipitation, which ensures a smooth and safe flight mission. A total of 128 geotagged points (image pairs) were captured with the drone and time spent in acquiring these image data was approximately 14 minutes.

For the TST survey, an in-situ check was first performed on the located existing control stations (QU01, QU04 and QU05). The stations were confirmed in-situ and were adopted for the survey connection. Points were picked around the stockpile at an interval of approximately $5 \mathrm{~m}$ but in cases where there are important details, it was picked at random. It is important to be sure that the height of the reflector is properly recorded because an erroneous input of height can greatly affect the accuracy of the result. For this study, the reflector height was constantly maintained at $3.50 \mathrm{~m}$ throughout the observation to avoid errors. At the base of the stockpiles, a total of 25 points were picked while about 33 points were picked at the top, making a total of 58 points. The time spent for the data acquisition was about 1 hour 12 minutes.

\section{Volume estimation from TS Data}

Several techniques can be used to estimate inventory size such as trapezoidal method for rectangular or triangular prism, classical trapezoidal cross-sectioning, Simpson's and improvement methods using Simpson-based, cubic spline, and Hermite cubic formula used for conventional volume computations. Nonetheless, the stockpile volume was measured using a computer methodology to avoid human computational errors, as recommended by Marco et al. (2012). The data obtained by the TST was modelled in ArcGIS environment by transforming the points cloud into a continuous surface representation derived from a spatial data structure created from the process of triangulation. The volume of the earthworks was thus estimated from the continuous representation.

\section{Volume Estimation from UAV Data}

The workflow of the image processing adopted for the generation of the 3D models that served as the base models for the volume estimation using UAV photogrammetry is presented in Figure 4.

The overlapping images were aligned immediately after importing them into the software 


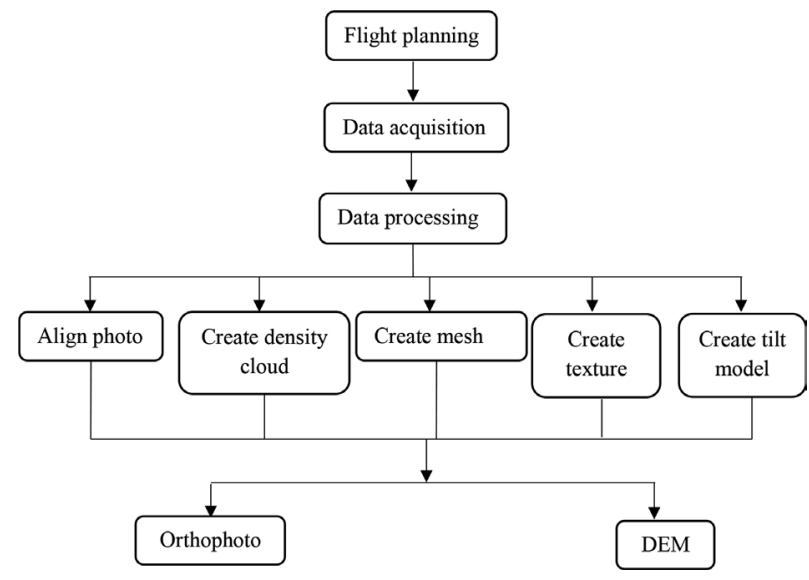

Fig. 4. Workflow of the UAV survey and data processing.

environment before other models were generated, such as the sparse and dense point cloud, the mesh and texture, and finally, the DEM and orthomosaic. The aligned images were georeferenced with three GCPs (QU01, QU04 and QU05), which were established around the stockpile. While processing the aerial photographs, dense points cloud was built from the camera positions obtained during the alignment of images. The construction parameter for the built dense point cloud include construction quality, which was set to 'medium' in order to minimize time required for processing of the aligned images due to insufficient memory of the computer system used for the image processing (Agisoft 2020). The depth filtering was performed in 'Aggressive' (Highest) mode during the building of the dense cloud in order to remove the outliers from the sparse points cloud. The Mesh was built with an Arbitrary (3D) surface type using the generated dense point cloud as data source, while the interpolation was disabled at this stage in order to achieve accurate reconstruction result since the reconstruction is majorly applicable to areas corresponding to the dense cloud points. Also, for the Mesh building, the quality and face count were each set at 'Medium', while the vertex colour calculation tool was enabled. It is important to build a 'Texture model' because it depicts how the object texture will be packed in texture atlas. While the mapping mode was set to 'Generic' in order to enable parameterization of the texture atlas for arbitrary geometry, blending mode was set to Mosaic (which is the default mode), while hole filling and ghost filtering were also enabled to improve the quality of the texture model. To generate the DEM, there is need to define the source data's coordinate system. A geographical coordinate system (WGS 84, ESPG::4326) was selected and the data source was defined as 'Dense cloud'. Again, interpolation was enabled (default) and the boundary definition was unchecked or disabled in order to model the entire quarry for further analysis. Orthomosaic of the area of interest was generated while Mosaic (default) was selected as the blending mode.

Also, for the estimation of the degree of uncertainties in the computed volumes, the standard deviation and standard error were computed and adopted. Each standard deviation is computed by considering both results of each stockpiles i.e. result of TST and UAV on each stockpiles using equation 1.

$$
S D=\sqrt{\frac{\delta_{X 1}{ }^{2}+\delta_{X 2}{ }^{2}+\delta_{X 3}{ }^{2}+\ldots+\delta_{X n}{ }^{2}}{(N-1)}}
$$

where:

- $\delta_{X}=(X-\bar{X})$

- $\quad X$ is expressed as measured value,

- $\bar{X}$ can be termed as mean of the measurement

The relative error of the measurement was also computed by comparing the total volume of each of the two methods (TST and UAV) with the standard volume of the stockpile using equation 2.

$$
E=\frac{\text { Observed volume }- \text { Expected volume }}{\text { Expected volume }} \times 100 \%
$$

\section{Results and findings}

Figures $5 \mathrm{a}(\mathrm{A}$ and $\mathrm{B})$ and $5 \mathrm{~b}$ presents the TIN model and DEM of the twin stockpiles produced from the TST data respectively, while the DEM produced from the UAV acquired overlapping images using Agisoft metashape is presented in Figure 6. The reconstructed DEM has a resolution of $4.42 \mathrm{~cm} \mathrm{pix}^{-1}$ and point density of $513 \mathrm{pts}$ $\mathrm{m}^{-2}$, while the TIN model was generated with the spatial details of the 58 points that were acquired during the field work. The volumes of the two stockpiles were then generated from these models. The calibration coefficients of the UAV camera and correlation matrix is presented in Table 
A

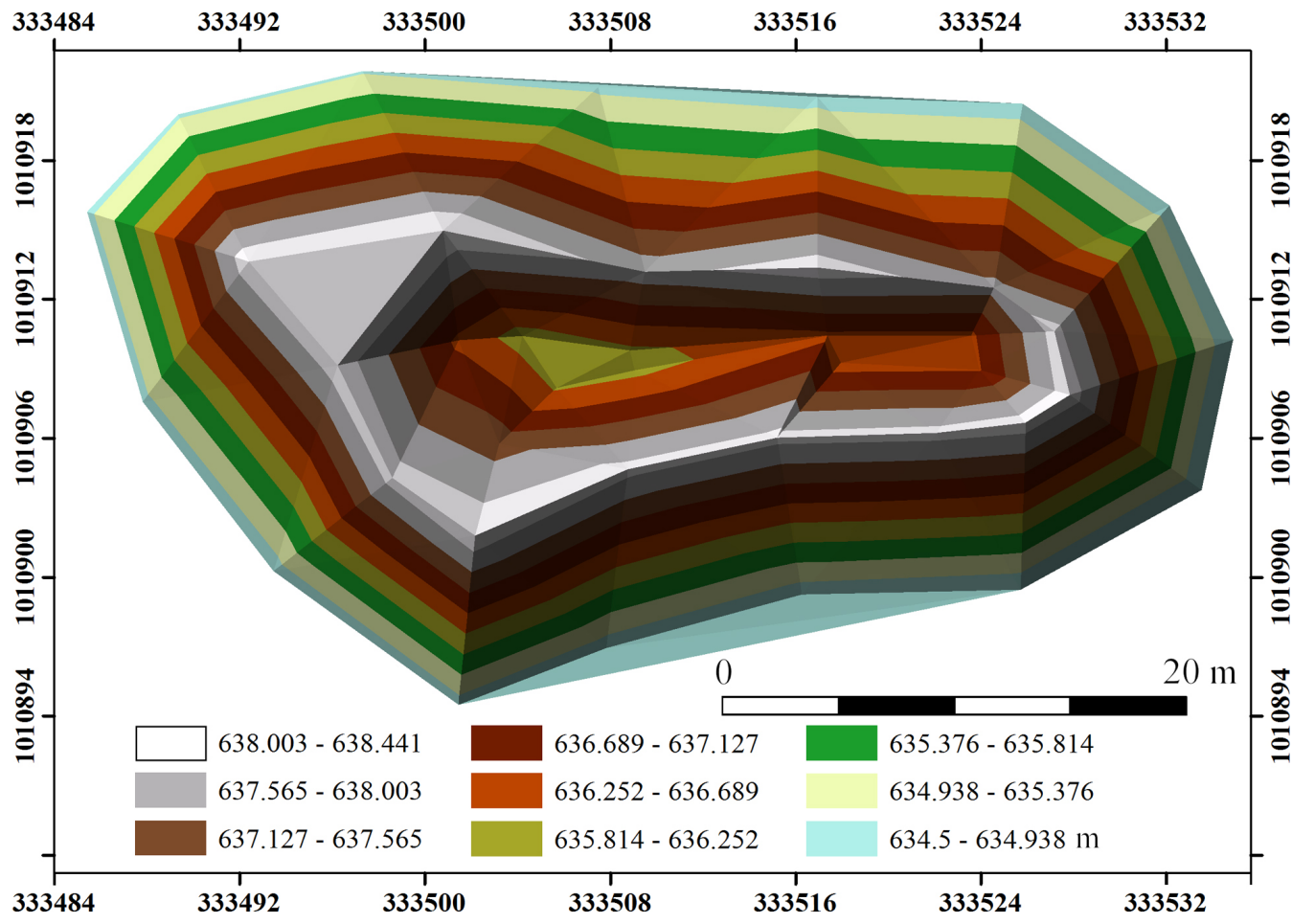

B

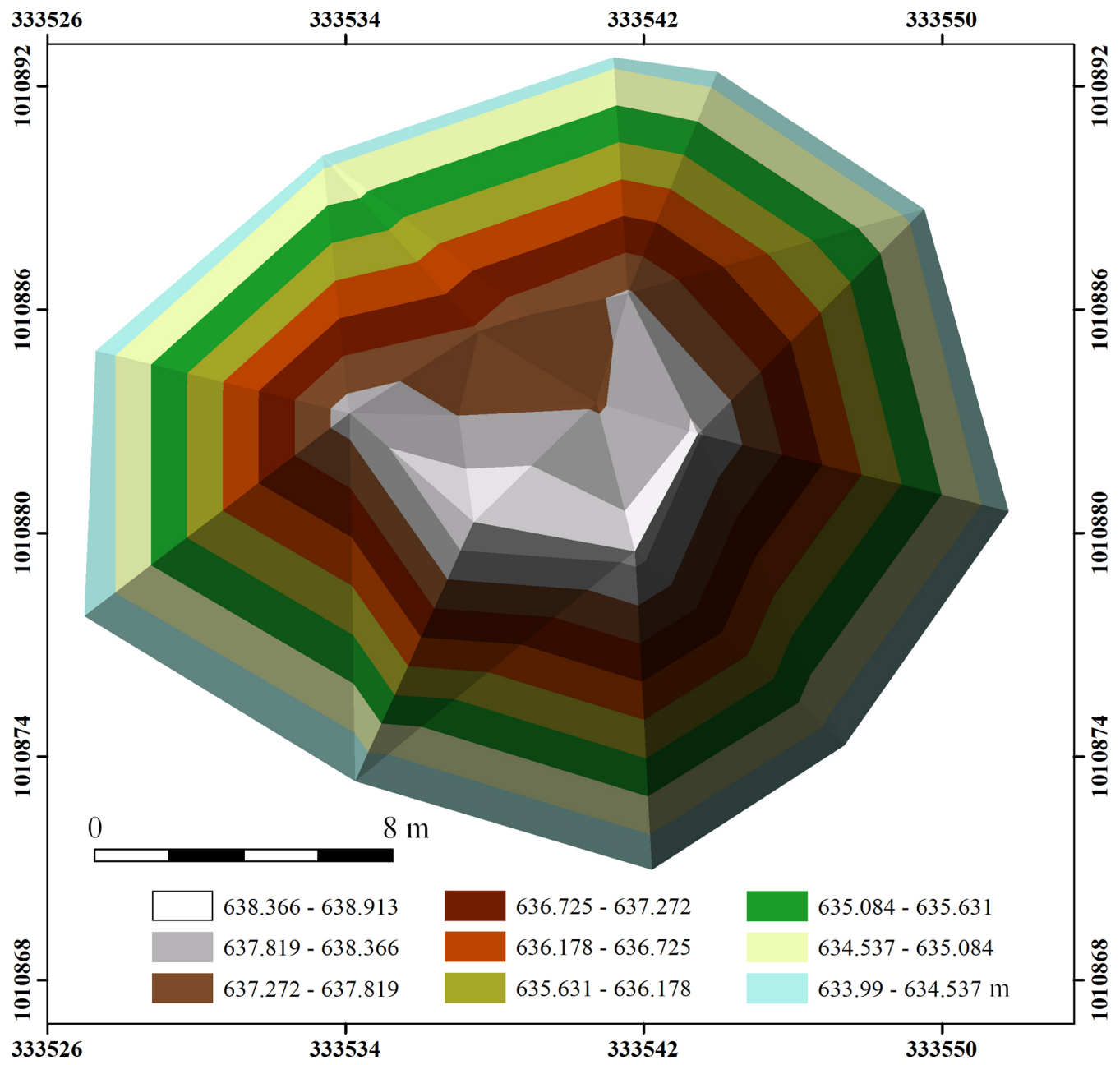

Fig. 5a. TIN model of the stockpiles A and B generated from ArcScene. 


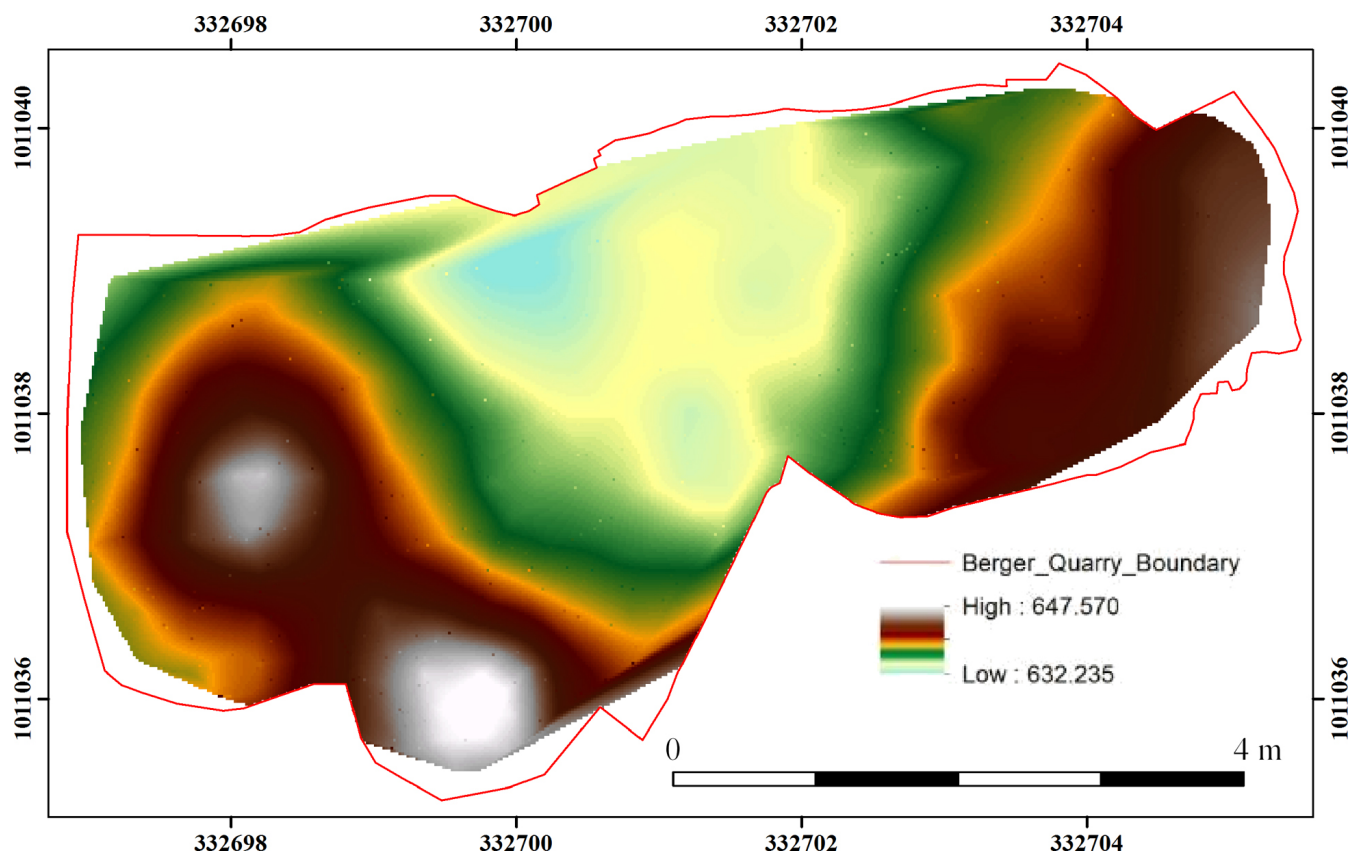

Fig. 5b. TST generated Digital Elevation Model of the stockpiles.

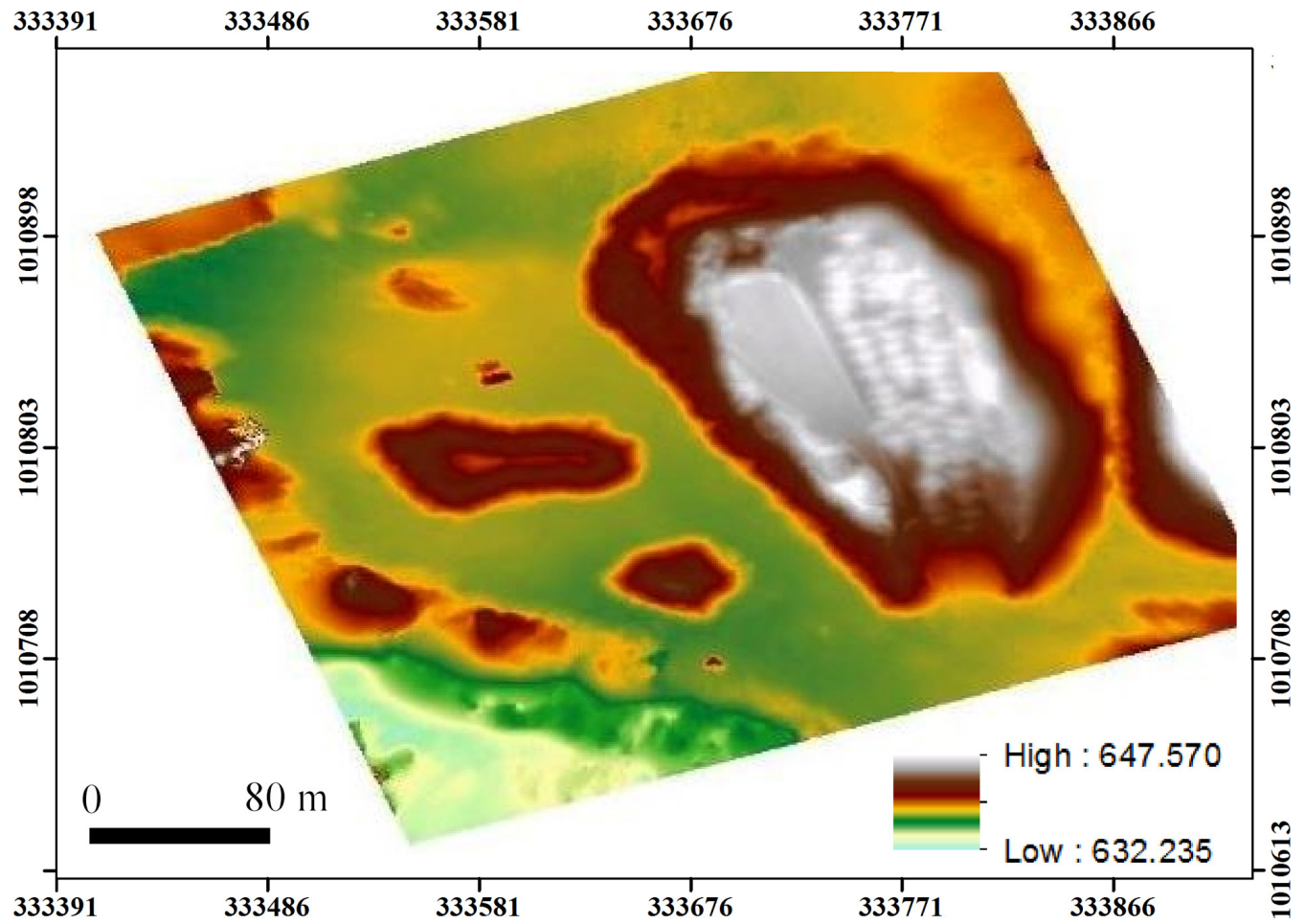

Fig. 6. DEM generated from Agisoft.

Table 2. The calibration coefficient and correlation matrix.

\begin{tabular}{|c|c|c|c|c|c|c|c|c|}
\hline & Value & Error & F & K1 & K2 & K3 & P1 & P2 \\
\hline F & 272.73 & 4.2 & 1.00 & 0.75 & -0.97 & 0.98 & -0.14 & 0.12 \\
\hline K1 & 0.230625 & 0.0008 & - & 1.00 & -0.84 & 0.84 & -0.64 & 0.49 \\
\hline K2 & -0.438133 & 0.0027 & - & - & 1.00 & -1.00 & 0.23 & -0.19 \\
\hline K3 & 0.252709 & 0.0023 & - & - & - & 1.00 & -0.22 & 0.18 \\
\hline P1 & -0.00342852 & $3.9 \mathrm{e}-005$ & - & - & - & - & 1.00 & -0.62 \\
\hline P2 & 0.00346376 & $3.2 \mathrm{e}-005$ & - & - & - & - & - & 1.00 \\
\hline
\end{tabular}


Table 3. Average camera location error.

\begin{tabular}{|c|c|}
\hline Camera location component & Error $[\mathrm{m}]$ \\
\hline $\mathrm{X}$ & 8.35685 \\
\hline $\mathrm{Y}$ & 9.07843 \\
\hline $\mathrm{Z}$ & 3.01858 \\
\hline $\mathrm{XY}$ & 12.3392 \\
\hline Total & 12.703 \\
\hline
\end{tabular}

2 where $\mathrm{F}$ is the focal length, $\mathrm{K} 1, \mathrm{~K} 2, \mathrm{~K} 3$ are the radial distortion coefficients while $\mathrm{P} 1$ and $\mathrm{P} 2$ are the tangential distortion coefficients.

The average camera location error for the image processing is presented in Table 3 . From the recorded errors, it was observed that while the altitude [Z] component of the camera location recorded the least error magnitude with an error value of approximately $3.02 \mathrm{~m}$, the Latitude $[Y]$ component of the camera location recorded the highest error magnitude with approximately $9.09 \mathrm{~m}$.

\section{Comparative Analysis based on Accuracy}

The volume of the two stockpiles estimated from both the TST-produced TIN and the UAVproduced DEM is presented in Table 4. It also presents the value of the volume obtained from the mill machine operator, which was used as the standard for the comparison. The volumes estimated from the TST approach and UAV approach were thus compared with the volume obtained from the mill machine and the differences were estimated in percentage.

For the estimation of the degree of uncertainties in the obtained result, TST yielded a volume standard deviation of $\pm 62.27 \mathrm{~m}^{3}$ for stockpile 1 , and UAV produced a standard deviation of $\pm 64.27 \mathrm{~m}^{3}$ for the same stockpile. In the case of stockpile 2 , standard deviation of $\pm 7.96 \mathrm{~m}^{3}$ was estimated for TST measurement, while UAV produced a standard deviation of $\pm 7.96 \mathrm{~m}^{3}$. Also, the estimated standard error for the TST volume $\left(\mathrm{E}_{\mathrm{TST}}\right)$ is $+2.9 \%$ while the estimated standard error for the UAV DEM ( $\left.\mathrm{E}_{\mathrm{TST}}\right)$ is $-2.3 \%$.

\section{Comparison of Results based on project execution time}

Though the volume of the stockpiles estimated from the UAV-generated DEM proved to be reliable in terms of accuracy, attempt was also made to evaluate the approximate time used to execute the project using each of the two approaches, and the result is presented in Table 5.

Table 5. Analysis of project execution time.

\begin{tabular}{|l|c|c|c|c|}
\hline \multirow{2}{*}{$\begin{array}{c}\text { Instru- } \\
\text { ment }\end{array}$} & $\begin{array}{c}\text { Instrument } \\
\text { setup }\end{array}$ & $\begin{array}{c}\text { Data acqui- } \\
\text { sition time }\end{array}$ & $\begin{array}{c}\text { Process- } \\
\text { ing time }\end{array}$ & $\begin{array}{c}\text { Total time } \\
\text { spent }\end{array}$ \\
\cline { 2 - 5 } [min] \\
\hline $\begin{array}{l}\text { Total } \\
\text { Station }\end{array}$ & 5 & 72 & 15 & 87 \\
\hline UAV & 5 & 14 & 45 & 59 \\
\hline
\end{tabular}

\section{Discussion of results}

The first stockpile yielded a volume value of $2031.31 \mathrm{~m}^{3}$ for the case of TST-produced TIN while the volume obtained from the UAV produced DEM was $1902.76 \mathrm{~m}^{3}$. For the second case, $799.41 \mathrm{~m}^{3}$ was obtained as the volume from the TST-produced TIN while $783.49 \mathrm{~m}^{3}$ was obtained as the volume from the UAV-generated DEM. A cumulative volume for the twin stockpiles of approximately $2830.72 \mathrm{~m}^{3}$ and $2686.25 \mathrm{~m}^{3}$ was obtained from the TST-produced TIN and the UAVproduced DEM, respectively, while the actual volume from the mill machine is $2750.00 \mathrm{~m}^{3}$. The percentage difference between the volume from

Table 4. Results of the comparative analysis of the volumes obtained from the TST-produced TIN and the UAV-produced DEM.

\begin{tabular}{|l|c|c|c|c|c|c|c|}
\hline Instrument & Model & $\begin{array}{c}\text { Stockpile 1 } \\
\text { approx. vol- } \\
\text { ume }\left[\mathrm{m}^{3}\right]\end{array}$ & $\begin{array}{c}\text { Stockpile 2 } \\
\text { approx. vol- } \\
\text { ume }\left[\mathrm{m}^{3}\right]\end{array}$ & $\begin{array}{c}\text { Total volume } \\
{\left[\mathrm{m}^{3}\right]}\end{array}$ & $\begin{array}{c}\text { Difference } \\
\text { between the ac- } \\
\text { tual volume and } \\
\text { cumulative esti- } \\
\text { mated volume }\end{array}$ & $\begin{array}{c}\text { Standard } \\
\text { deviation }\end{array}$ & $\begin{array}{c}\text { Standard er- } \\
\text { ror (degree of } \\
\text { uncertainty) }\end{array}$ \\
\hline $\begin{array}{l}\text { Actual } \\
\text { volume from } \\
\text { mill machine }\end{array}$ & & & 2750.00 & & & \\
\hline Total station & TST TIN & 2031.31 & 799.41 & 2830.72 & 80.72 & \pm 70.23 & $+2.9 \%$ \\
\hline UAV & UAV DEM & 1902.76 & 783.49 & 2686.25 & -63.74 & \pm 72.23 & $-2.3 \%$ \\
\hline
\end{tabular}


the Total Station instrument and the actual volume is $2.9 \%$ while the percentage difference between the volume from the UAV and the actual volume of the stockpile is $-2.3 \%$. The percentage difference obtained when the volume estimated from the UAV-produced DEM is less than the $4.5 \%$ difference obtained by Blistan et al. (2020), and less than the $3 \%$ maximum allowable difference recommended by Raeva et al. (2016), which confirms the high accuracy of the UAV method. It can also be observed that the percentage difference of the volume obtained from the comparison of the UAV-produced DEM and the actual volume is less than the percentage difference of the volume obtained from the comparison of the TST-produced TIN and the actual volume. This implies that the result of the UAV approach is more accurate when compared to the result of the TST approach. The reason for this more accurate result of the UAV approach could be attributed to the inability of the TST approach to generate very dense points cloud unlike the UAV approach, which is capable of generating very dense points cloud. For this study, while only 58 points cloud were generated by the TST approach and used for the construction of the TIN model, the point density of the DEM generated by the UAV approach is about $513 \mathrm{pts} \mathrm{m}^{-2}$. Also, Akwaowo et al. (2019) stressed that insufficient number of points tends to increase the size of triangles in a TIN surface, which affects the accuracy of the volume, while large number of points cloud (dense point cloud) are obtainable from the UAV approach, which results in more accurate interpolation. Furthermore, it was also observed that the TST approach overestimated the volume of the twin stockpiles when compared to the most probable value of the volume (volume from the mill machine). These findings are also consistent with the results obtained from the experiments conducted by Arango and Morales (2015) and Urban et al. (2019), and it affirms that UAV data source is indeed a veritable source for accurate stockpile volumetric estimation.

The result of the project execution time analysis shows that the UAV approach for stockpile volumetric estimation is not just reliable in terms of accuracy but also highly economical in terms of time. In this study, an approximate total execution time of 59 minutes was expended on the project using the UAV approach while 1 hour and 27 minutes was expended on the same project when ground survey approach using a Total Station was adopted. This result also corresponds with the findings of Arango and Morales (2015), and Fitzpatrick (2015).

Since two different non-invasive technologies with different measurement sensors have been used for this study, a measure of uncertainties would have been introduced into the estimated or obtained results due to errors associated with the different accuracy of each of the two measurement sensors, possible slight deviation of the UAV during the flight mission (IMU), occurrence of noise in the generated point cloud, and the accuracy of the DEM generation. The obtained degree of uncertainty in the estimated TST volume $(+2.9 \%)$ and the estimated UAV volume $(-2.3 \%)$ as presented in Table 4 corresponds to the findings of Kociuba (2020) which affirmed that the degree of uncertainty should not exceed $2 \%$ of the estimated values, especially when it is associated with the accuracy of the DEM generation, based on the filtering of noise inherent in the point cloud.

Generally, the findings of this research corresponds with the findings of Kovanič et al. (2020) which affirms that the main advantages of UAV approach are the speed of measurement in the field; the completeness of the final data; high density of the obtained point cloud; and the low cost of the used UAS while its main disadvantages are higher hardware requirements for image processing and longer processing time.

\section{Conclusion}

In this study, the applicability and robustness (in terms of accuracy and time) of unmanned aerial vehicle for earthwork volume estimation was investigated. Specifically, it explored the application of high-precision non-invasive survey technologies (conventional ground-based survey using Leica TS06 Total Station and UAV photogrammetry approach using DJI Mavic Air) for the assessment of the volume of earthworks, using a twin stockpile situated in a quarry site as a case study. The results of the estimated volume of the twin stockpiles using these two approaches was compared to the actual volume of the twin stockpile obtained from the mill machine, while 
the time expended for the instrument setup, data acquisition and processing was recorded for each of the two methods. The result of the comparative analysis shows that the UAV approach presents more accurately estimated volume of the twin stockpile and it proved to be more economical in terms of project execution time.

Contrary to conventional methods of earthwork volume estimation that provide limited number of points required for accurate surface modelling, the UAV approach provides very dense point clouds which leads to more accurate interpolation in the generation of 3D models, and by extension, significantly improves the accuracy of the volume estimated from the models. The UAV approach is both more accurate and time efficient for the estimation of the volume of stockpiles when compared to the conventional survey methods or approaches.

\section{Acknowledgments}

The authors would like to thank the expert anonymous reviewers, and the journal editor for their constructive comments and suggestions.

\section{References}

Ab Rahman A.A., Abdul-Maulud K.N., Mohd F.A., Jaafar O., Tahar K.N., 2017. Volumetric calculation using low cost unmanned aerial vehicle (UAV) approach. IOP Conf. Series: Materials Science and Engineering 270: 1-6. DOI 10.1088/1757-899X/270/1/012032.

Agisoft, 2020. Configuration parameters. Online: agisoft. freshback.com/support/solutions/articles/3100 (accessed November 1, 2020).

Ajayi O.G., Palmer M., Salubi A.A., 2018. Modelling farmland topography for suitable site selection of dam construction using unmanned aerial vehicle (UAV) photogrammetry. Remote Sensing Applications: Society and Environment 11: 220-230. DOI 10.1016/j.rsase.2018.07.007.

Ajayi O.G., Salubi A.A., Angbas A.F., Odigure M.G., 2017. Generation of accurate digital elevation models from UAV acquired low percentage overlapping images. International Journal of Remote Sensing 8-10(38): 3113-3134.

Akwaowo U.E., Aniekan E.E., Okon U., 2019. A comparative analysis of volumetric stockpile from UAV photogrammetry and total station data. SSRG International Journal of Geoinformatics and Geological Science 6(2).

Arango C., Morales C.A., 2015. Comparison between multicopter UAV and total station for estimating stockpile volumes. The International Archives of the Photogrammetry, Remote Sensing and Spatial Information Sciences XL-1/N4.

Baiocchi V., Dominici D., Mormile M., 2013. UAV application in post - seismic environment, The International Archives of the Photogrammetry, Remote Sensing and Spatial
Information Sciences XL-1/W2, 21-25. DOI 10.5194/isprsarchives-XL-1-W2-212013.

Blistan P., Jacko S., Kovanič L., Kondela J., Pukanská K., Bartoš K., 2020. TLS and SfM approach for bulk density determination of excavated heterogeneous raw materials. Minerals 10: 174. DOI 10.3390/min10020174

Borgelt S.C., Harrison J.D., Sudduth K.A., Birrell S.J., 1996. Evaluation of GPS for applications in precision agriculture. Applied Engineering in Agriculture 12(6): 633-638.

Bremer M., Sass O., 2012. Combining airborne and terrestrial laser scanning for quantifying erosion and deposition by a debris flow event. Geomorphology 138: 49-60.

Ding G., Wu Q., Yao Y.D., 2015. Byzantine attack and defense in cognitive radio networks: A survey. IEEE communication survey and tutorials 17(3): 1342-1363.

DJI, 2019. Mavic Air Specs. Online: www.dji.com/mobile/ mavic-air (accessed November 1, 2020).

Eisenbeiß H., 2009. UAV Photogrammetry. Institute of Geodesy and Photogrammetry (PhD Dissertation), ETH Zurich, Switzerland.

Fitzpatrick B.P., 2015. Unmanned Aerial System for survey and mapping: cost comparison of UAS versus traditional methods of data acquisition (Masters Dissertation). Faculty of USC Graduate School, University of Southern California.

Ioanna S., Apostolos T., 2015. The use of Unmanned Aerial Systems (UAS) in Agriculture. Proceedings of the 7th International Conference on Information and Communication Technologies in Agriculture, Food and Environment, Kavala, Greece: 730-736.

Kavanagh B., Glenn Bird S.J., 1996. Surveying: Principle and Application. $3^{\text {rd }}$ Edition, Pearson.

Kociuba W., 2017. Analysis of geomorphic changes and quantification of sediment budgets of a small Arctic valley with the application of repeat TLS surveys. Zeitschrift für Geomorphologie 61(2): 105-120.

Kociuba W., 2020. Different paths for developing terrestrial LiDAR data for comparative analyses of topographic surface changes. Applied Sciences 10: 7409.

Kovanič L., Blistan P., Urban R., Štroner M., Blišt'anová M., Bartoš K., Pukanská K., 2020. Analysis of the Suitability of High-Resolution DEM Obtained Using ALS and UAS (SfM) for the Identification of Changes and Monitoring the Development of Selected Geohazards in the Alpine Environment - A Case Study in High Tatras, Slovakia. Remote Sensing. 12(23): 3901.

Lin L.S., 2004. Application of GPS RTK and total station systems on dynamic monitoring land use. Proceedings of the ISPRS Congress Istanbul, Turkey.

Marco C., Aracena P., Chung W., 2012. Improving accuracy in earthwork volume estimation for proposed forest roads using a high-resolution digital elevation model. Croatian Journal of Forest Engineering 33(1): 125-142.

Nourbakhshbeidokhti S., Kinoshita A.M., Chin A., Florsheim J.L., 2019. A Workflow to Estimate Topographic and Volumetric Changes and Errors in Channel Sedimentation after Disturbance. Remote Sensing 11: 586. DOI 10.3390/ rs11050586

Pflipsen B., 2006. Volume Computation: A comparison of Total Station versus Laser Scanner. (Masters Dissertation). Department of Technology and Built Environment, University of Gävle, Sweden.

Propeller, 2018. How stockpile volume measurement works in drone surveying with propeller. Online: www.propelleraero.com/blog/how-stockpile-volume-measurementworks-in-drone-surveying/ (accessed September 5, 2019). 
Raeva P.L., Filipova S.L., Filipov D.G., 2016. Volume computation of a stockpile - A study case of comparing GPS and UAV measurement in an open pit quarry. The International Archives of the Photogrammetry, Remote Sensing and Spatial Information Sciences, XLI-B1, XXIII.

Šašak J., Gallay M., Kaňuk J., Hofierka J., Minár J., 2019. Combined use of terrestrial laser scanning and UAV photogrammetry in mapping alpine terrain. Remote Sensing 11(18): 2154

Siebert S., Teizer J., 2014. Mobile 3D mapping for surveying earthwork projects using an Unmanned Aerial Vehicle (UAV) system. Automation in Construction 41: 1-14.
Siriba D.N., Matara S.M., Musyoka S.M., 2015. Improvement of volume estimation of stockpile of earthworks using a concave hull-footprint. Micro Macro \& Mezzo Geo Information 5: 11-24. UDC: 528.718.021.7:624.1.

Stalin L.J., Gnanaprakasam R.P.C., 2017. Volume Calculation from UAV based DEM. International Journal of Engineering Research \& Technology 6(6): 126-128.

Urban R., Štroner M., Blistan P., Kovanič L., Patera M., Jacko S., Duriška I., Kelemen M., Szabo S., 2019. The suitability of UAS for mass movement monitoring caused by torrential rainfall - a study on the Talus Cones in the Alpine terrain in high Tatras, Slovakia. ISPRS International Journal of Geo-Information 8: 317. DOI 10.3390/ijgi8080317. 